\title{
The Role of Digital Technologies for Regional Development: a System Dynamics Analysis
}

\author{
Elpida Samara ${ }^{1}$ D $\cdot$ Anastasios Andronikidis $^{2} \cdot$ Nicos Komninos $^{3}$. \\ Yiannis Bakouros ${ }^{1}$. Efthymios Katsoras ${ }^{4}$
}

Received: 5 January 2022 / Accepted: 19 January 2022

(c) The Author(s) 2022

\begin{abstract}
The unprecedented development of the information and communication technologies sector has accelerated the spectacular changes in societies and employment trends worldwide. The adoption of ICTs in innovation systems has been a key factor in the overall competitiveness of economic regions and national economies. This paper studies the impact of ICT on regional development. To do so, a modelling approach is used to develop a framework-guidance tool that can formulate what-if scenarios of smart technology enhancement in a regional innovation system. The model is applied in two Greek regions with different development backgrounds, and the findings emphasise the importance of smart technologies in regional development in both cases.
\end{abstract}

Keywords Regional development $\cdot$ Innovation dynamics $\cdot$ System dynamics modelling

Elpida Samara

esamara@uowm.gr

Anastasios Andronikidis

aandronikidis@uowm.gr

Nicos Komninos

komninos@urenio.org

Yiannis Bakouros

ylb@uowm.gr

Efthymios Katsoras

katsorae@auth.gr

1 Department of Regional Development and Cross Border Studies, University of Western Macedonia, Koila, Kozani, Greece

2 Department of Mechanical Engineering, University of Western Macedonia, Sialvera \& Bakola, Kozani, Greece

3 Urenio Research, Aristotle University of Thessaloniki, Thessaloniki, Greece

4 Department of Mechanical Engineering, Aristotle University of Thessaloniki, Thessaloniki, Greece 


\section{Introduction}

Many scholars have dealt with the concept of innovation systems. Innovation system theory has emerged from studies on micro-level technology systems, from studies on innovation systems and innovation through interactive learning at mid- and macro-level (Edquist, 1997; Freeman, 1987; Lundvall, 1992; Nelson, 1993) and through several EU and OECD publications (OECD, 1999), from which the concept of the National Innovation System (NIS) was promoted. Since the approaches of Freeman, Lundvall and Nelson (Freeman, 1987; Lundvall, 1992; Nelson, 1993), the concept has undergone several changes that shift from national to regional, sectoral/technological, or even global level. Nowadays, the concept of innovation systems has evolved into a useful tool for analysing economic growth. The most studied form of innovation systems in the literature is the national innovation system. However, there are many scholars who argue that the focus at regional level is enhanced if one identifies the complexity of national systems and the level of differentiation of individual regional productive systems (Sefertzi, 1998). In addition, the literature often reveals that the concept of a discreet regional system can play a balanced role in the age of increasing globalisation, which demonstrates the tendency to homogenise culture and directions in strategies and solutions (Niosi, 2000a, b ).

In the present study we focus on the concept of Regional Innovation System (RIS), which constitutes a key tool for formulating and implementing research and innovation policies at a regional level. According to Niosi (Komninos, 2018), RISs have two important characteristics. Firstly, they are a combination of public policies and secondly, they constitute a spontaneous development of skills in the market. These characteristics have made the RIS approach an appropriate framework for the study of economic development and competitiveness at regional level.

In terms of policymaking, the European Commission, starting in the early 1990s, has introduced a family of policy programs that have given a strategic view of technology and innovation at regional level. Regional Infrastructure and Technologies for Innovation and Technology Transfer (RITTS), Regional Technology Plans (RTP) and Regional Innovation Strategies (RIS strategy) provided co-financing and guidance to regional governments in assessing their regional potential and defining strategies to promote cooperation and the potential of the small business sector, the research and technology community and public authorities to achieve Regional Development. Today, the new 2014-2020 growth strategy includes Research and Innovation Strategies for Smart Specialization (RIS3). These strategies, which are based on the principles of the Europe 2020 strategy for smart, sustainable and inclusive growth, aim to achieve high levels of employment, productivity and social cohesion in the EU and the Member States.

The above bibliographic reference concerns the concepts of the region, the innovation system at regional level and the innovation policies, which today are renamed as smart specialisation strategy. A new notion, smart cities, is introduced to the aforementioned. According to the literature, the smart city is the foundation for the long-term growth of urban centres and ensures their expansion under sustainable conditions. Smart cities are part of a larger strategy for Western societies to get access to the knowledge economy. They are spaces that help people be more creative, learn new things and innovate. They are formed by combining digital networks and information society applications with local 
innovation systems working within cities (technology districts, technology parks, innovation poles and clusters). Their value lies in the ability to bring together and combine three forms of intelligence: human of urban population, collective of innovation institutions, and artificial of digital networks and applications.

The term intelligent cities/smart cities is used to describe areas cities, regions, city districts and clusters in which the local innovation system is supported and upgraded through digital networks and applications (Sotirelis et al., 2021). With the use of information and communication technologies, the innovation system acquires greater depth and scope, while its functions become more transparent and efficient. According to the study by Komninos (2018), there are three key components of smart cities: the innovation system (local/regional) of the reference area, smart technologies, and the reference area, the city.

This research aims to investigate the use of smart technologies in regional innovation systems and its impact on regional development. The methodological tool used is systems dyamics. The literature shows that the approach of the concept of RIS with the theory of system dynamics is particularly successful. In particular, a study by Viale and Pozzali (Viale \& Pozzali, 2010) reported the existence of two main reasons for a systematic approach to the analysis of RISs. The first is that each RIS has its own specific characteristics. The second is that it is considered necessary to give a dynamic description of the formation of a RIS in order to predict its possible evolution. This implies that RISs consist of multiple dimensions (variables), each of which is associated with its own rhythm and direction of change, and which are causally related to the production of patterns of change in each system (McCarthy et al., 2010).

A more general question that this research aims to answer is whether the use of smart technologies in a RIS benefits regional development, defined and measurable by specific indicators. More specifically, the questions posed by this research are the following:

1. How can the use of smart technologies improve the efficiency of the regional innovation system and more vigorously promote regional development processes.

2. How can the dynamic model illustrate the multiple relationships between smart technologies, open innovation systems and regional development.

This research comes to fill a scientific gap regarding the study of the impact of digitisation on open innovation systems with the use of simulation. With the model that is created, the authors believe that the stage will be set for the next programming period 2021-2027, where the smart specialisation agenda and the RIS3 strategy will reach a more mature stage, allowing higher quality and more up-to-date strategies. In addition, the results of the research can contribute to the effort to strengthen the regional innovation system. That is so since the contribution of the model that has been developed is very important, as it can be used as guide/framework for the formulation of policies and tactics aimed at innovative action at regional level. This may enable the identification of strengths or weaknesses within the system and allow policy makers to reinforce the points with the most significant multiplier benefits in regional development.

The paper is structured as follows. We begin with the introductory section where the purpose of our study is reflected as well as the gap that our research 
fills. The 'The Concepts of RIS, Regional Development and Smart Technologies' section describes the theoretical concepts of this research, namely RIS, regional development and smart technologies. The 'Methodology' section provides the methodological approach of the research and in particular the information on system dynamics, the selection of indicators used in the model to capture regional development, and the forecasting techniques used for variables for which there were no data available in the literature. The 'The Systemic Overview of RIS' section provides the generic structure of RIS and the modelling of the innovation system. In particular, the 'The Systemic Overview of RIS' section contains the causal loop diagram, the mathematical formulation, the structural validity, the initial conditions and the units of measurement. Based on simulation results, the 'The Effect of Smart Technologies on the Regional Development-the Case of Two Greek Regions' section depicts the results for regional development of the two Greek regions under study for a period of 10 years under what-if scenario analysis regarding ICT indicators. The article concludes with the main findings that emerge from the results of the simulations, as well as implications for future research.

\section{The Concepts of RIS, Regional Development and Smart Technologies}

In today's Information Society, growth and competitiveness are based on the assimilation and use of smart technologies. The area in which the development of smart technologies can primarily contribute is that of regional policy. The rapid development of digital technology and especially of Information and Communication Technologies poses many challenges for smart, sustainable and inclusive development, and is therefore a crucial initiative for the Europe 2020 strategy. Moreover, the ability to adapt technology and entrepreneurial strategies to the environment in which it operates seem to be necessary practices in knowledge-based innovation, prioritisation and decision-making processes, for smart, sustainable and inclusive solutions (Carayannis et al., 2021a). More and more governments around the world are planning and implementing ICT adoption through specific digital development strategies aimed at improving efficiency and transparency in public administration, stimulating new entrepreneurship with stronger innovation and export activity, and improving the quality of life. New technologies, and especially ICT, are shaping a new business environment that represents the so-called transition to a digital economy that creates new value-added business opportunities, and contributes to various dimensions of an economy's growth process.

For policymakers, it would be very important if the penetration of ICT in companies and the creation of relevant infrastructure could be linked to job creation, improving competitiveness and boosting export activity. In particular, it is expected that investments in ICT, the improvement of electronic skills (e-skills) of the workforce, the activation in terms of demand for innovation from the public sector, and also the reform of the regulatory and legal framework for the digital economy that will act as growth drivers of the economy at local, regional and national level, provided that the appropriate support policies are implemented. The conceptual 
framework of the present study focuses precisely in the role of smart technologies on regional development.

To do this we focus on the regional innovation system. Innovation is not just an individual act of learning from one company or another, but it is embedded in a larger system that allows and triggers the innovation process. Moreover innovation processes constitute a critical factor for the adequate application of technology in general and knowledge-sharing in particular (Kilintzis et al., 2020). Thus an innovation system includes all the important factors and institutions that contribute to the creation, development, diffusion and use of innovations and interfaces as well as the interactions of all these factors and institutions (Nauwelaers \& Wintjes, 2008).

Lundvall points out that innovation systems are open, social and dynamic (Lundvall \& Battese, 2000). They are open which means that innovations are produced as a result of interaction between economic actors. This means that they are systems interacting with their environment. They are social in the sense that 'they are based on an institutional environment; structured by laws, social terms, cultural models, habits, attitudes, technical models, etc.' Lundvall \& Battese, 2000). They are dynamic because of the 'financial flows between government and private organisations, human resources flows between universities, corporations and government laboratories, also because of regulatory flows from government to innovation agencies related to innovation' (Niosi, 2000a, b). An innovation system can be analysed at (1) sectoral, (2) regional, (3) national as well as (4) international level. The analysis of the actors and institutions of each level is a complement to the analysis of the actors of innovation at the other levels.

RISs are often made up of a collection of interconnected private, semi-private and public organisations that operate together under an institutional framework. This framework encourages the creation, use and transmission of information, as well as the development of new regional activities (Asheim \& Coenen, 2005; Cooke, 2004; Doloreux, 2003).

In the literature, there are many attempts that try to capture the research that is carried out in a RIS. According to Doloreux and Parto (Doloreux \& Parto, 2005), RIS research focuses on three main dimensions: the interactions between the actors of the innovation system (organisations and institutions) which are related to the exchange of knowledge; the creation and role of institutions that support knowledge exchange and innovation within a region and the role of a RIS in shaping regional innovation policies. According to Autio (Erkko, 2005), the RIS includes five dimensions: the 'subsystem of application and exploitation of knowledge' (innovative industries/companies); the 'knowledge production and dissemination subsystem' (higher education, research centers and other 'intermediaries') (Jeremy, 2006); intensive interactions between subsystems in terms of scientific/applied knowledge and human resource flows, including relationships with other regional and national institutions; high-quality infrastructure and institutional arrangements, including adequate 'regional' autonomy (Cooke et al., 1998) and 'regional policy actors' (Todtling \& Trippl, 2005).

According to Komninos (2006), the components of a RIS (such as innovative businesses, suppliers, customers, universities, research institutions, technology transfer organisations, etc.) may be used to describe its structure; its knowledge 
networks, divided into explicit and implicit ones; the institutions and the result of innovation (such as cooperative $\mathrm{R} \& \mathrm{D}$, strategic intelligence, product innovation, process innovation, the creation of technoblasts, etc.). Since open innovation can be seen as a specific approach covering the links that innovating firms forge with other organisations, innovations systems use the open innovation paradigm.

There are, however, new terminology associated with global, national and regional development today. Innovation-driven growth, knowledge-based growth and smart growth are the three types of growth. Business clusters are transformed into nodes of knowledge creation and learning on the way to becoming knowledge-intensive economies, culminating in global nodes of knowledge. On the other hand, smart growth is a key element of the EU 2020 strategy for maintaining employment, research, education, broadband and environmentally friendly and inclusive growth. Smart growth must be achieved through the convergence of innovation and digital strategies, called 'Research and Innovation Strategies for Smart Specialization (RIS3)' and 'Digital Development Strategies (DGSs)'. In this perspective, innovation and smart environments are levers for a new growth model, defined by specialisation, business intelligence and discovery, evidencebased development, bottom-up governance, extensive use of smart technologies and collaborative business models.

According to Sharma (2014), digital environments are driving a massive surge of growth at all levels, fueled by digital networks, software and new media. The intersection of innovation and digital systems generates a development model known as 'smart growth', which is quickly gaining traction throughout the world. So, because of the Internet and the World Wide Web, many of these physical systems become cyber-physical. 'Cyber-physical systems (CPSs) are physical systems and engineering systems whose functions are monitored, coordinated, controlled and integrated by a core of computing and communication' (Rajkumar, 2010). Innovation systems today have been transformed into cyber-physical systems, due to the proliferation and widespread use of digital technologies and the creation of digital media in decision making.

In the present research, in order to develop the model of the regional innovation system, we rely on the theory of the cyber-physical innovation system (CPS) developed by Geels (2002) and enriched with the theory on regional innovation systems by Komninos (2006). The concept of 'socio-technical regimes', which refers to the semi-coherent set of rules used by different social groups engaged in the innovation process, lies at the heart of this system (users, policymakers, social groups, suppliers, scientists, innovation intermediaries, financial institutions, companies and others). Moreover, the existence of networks in innovation systems are more widely used in the open innovation era and this in turn means a need for stronger linkages between the actors of a RIS. Diverse operators working through digital communication networks, virtual clusters and online services enhance all of these components that make up the regional innovation system. Moreover, the convergence of AI-enabled emerging technologies across all sectors has been creating and diffusing conditions that serve as catalysts and accelerators of socioeconomic, socio-technical and socio-political trans-formation across regions (Carayannis et al., 2021b). 
Taking into account all the above a significant research gap emerges in imprinting the interconnection between open innovation, regional development and digital systems and strategies in a holistic model. The model that is developed in this research aims to study the impact of digital technologies and strategies on regional development, as smart environments fill gaps in the innovation supply chain, providing virtual connectivity and resources where local resources and skills are lacking.

\section{Methodology}

This study is based on a 15-month research project for young researchers, entitled 'Support for Researchers with an Emphasis on Young Researchers-Cycle B' under the auspices of the Operational Program for Human Resources Development, Training and Lifelong Learning 2014-2020. The researchers conducted an in-depth literature review on the need to use smart technologies as a key component of a regional innovation system and their impact on regional development. The methodology used in this article to built and codify the model of regional development is system dynamics. Because we apply these tools to the behavior of human systems, as well as to physical and technical systems, systems dynamics draws attention to cognitive and social psychology, economic and other social systems (Sterman, 2000). Innovation systems are social systems because they are made up of social actors (institutions and organisations) (Johnson, 1997). Social systems are, by their very nature, dynamic and open to external interaction (Lundvall, 1992). This means that they can be changed and modified by the environment in which they operate in an irreversible way. Moreover, innovation systems are getting more complex and hence require more sophisticated models, with not only sequential but also parallel feedback processes to be involved within (Kilintzis et al., 2020). At the regional level, the literature states that there are two reasons to favor a systemic approach to the analysis of RISs (Viale \& Pozzali, 2010). According to the first one, each specific RIS has its own characteristics. The second one states that it is necessary to give a dynamic description of the formation of a RIS in order to predict its possible evolution. This perspective implies that RISs consist of multiple actors (variables), each of which is associated with its own rate and direction of change, which are causally related to the production of patterns of change in each system (McCarthy et al., 2010). In addition, from the extensive literature review it was observed that the simulation appears to offer significant capabilities for process modeling. Without simulation, the unique ability to control and improve the behavior of a system is possible through the process of experimental verifications which might be complex, time consuming and costly. Therefore, simulation of scenarios is needed in order to select the best solution for the system under study. SD process is divided into two phases, namely the qualitative and the quantitative analysis of the system (Coyle, 1996). In the first phase, a causal-loop diagram is designed, which is then converted to a stock and flow diagram. In the second phase, the stock and flow diagram is translated into a simulation program, which is then verified and confirmed. The program is implemented for alternative scenarios and the results are analysed. Following the above phases, we created the RIS model presented in the study, codified with 
the use of sytem dynamics, which aims at helping policy-makers in a regional level to formulate the appropriate policy strategy to enhance regional development.

The mathematical model that has been developed is characterised by a number of interactions between variables. Many of these interactions have appeared in other models of the literature. However, in the model of the present dissertation, all of them are gathered together, while interactions are studied for which no reference is made in the literature. In order to determine the validity of the model, the validity tests of the model took place as mentioned in the 'The Effect of Smart Technologies on the Regional Development - the Case of Two Greek Regions' section (Forrester, 1961). Also, the parameters were evaluated. The parameter values come from a series of indicators from the literature and more specifically from: the European Innovation Scoreboard (EIS), Eurostat, OECD (Organization for Economic Co-operation and Development), the National Statistical Office and the Global Competitiveness Report-World Economic Forum. The model was applied in the RIS of the two greek regions taking as initial values of the parameters those for the year 2020. We then evaluated the parameter values of the model and performed a series of tests to determine its validity. Finally, in the 'The Effect of Smart Technologies on the Regional Development - the Case of Two Greek Regions'section, two policy scenarios per region were developed, based on the literature and used the model to study their impact on the performance of regional development in the 2 regional systems under study.

\section{Regional Development Parameters}

Recent theories of regional development focus on human and economic capital, innovation and spatial dynamics - demographic change-as key elements for understanding regional development (Eversole \& Martin, 2005). A total of three indicators from the literature were used to configure regional development, which are the following:

1. Population change by NUTS 2 region, Eurostat.

2. Tertiary educational attainment, age group 25-64 by sex and NUTS 2 regions, Eurostat.

3. Real growth rate of regional gross value added (GVA) at basic prices by NUTS 2 regions, Eurostat, as well as the input from product and process innovation, which are state variables in our model.

The time interval chosen for investigation corresponds to the period of 2020-2030. IBM SPSS Expert Modeler has been used as a method to forecast the values to 2030, automatically calculating the best-fitting model for each dependent variable. Model variables are transformed where appropriate using differencing and/ or a square root. Regarding the predicted variables of the decade 2020-2030, an initial finding is that the most developed region of Central Macedonia presents significantly higher predicted values of all the variables that are being tested, since the observed values until 2021 show a seriously higher level for all involved variables. 

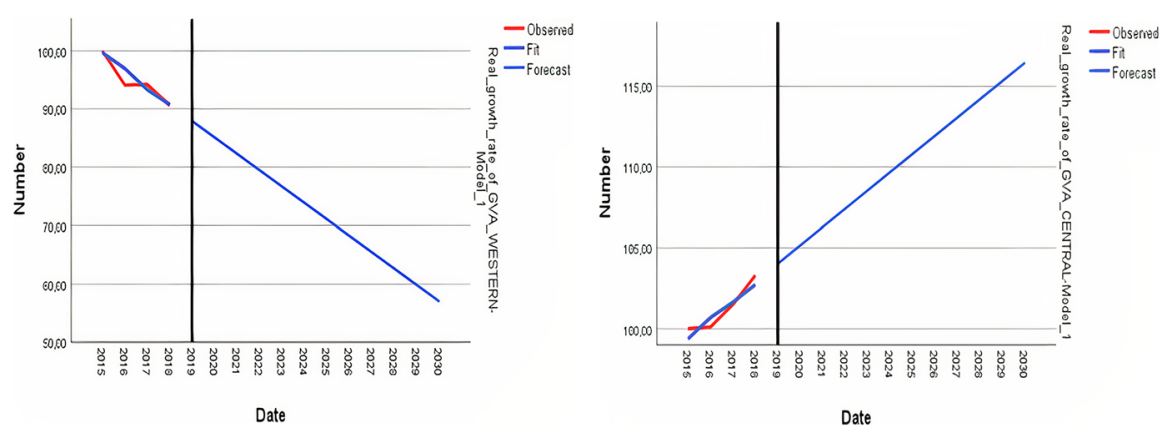

Fig. 1 Real growth rate of GVA by NUTS2 regions observed and forecast values for Central and Western Macedonia

A clearly reversed tendency between the two regions is shown in Fig. 1, presenting the observed and the forecast values for the real growth rate of GVA by NUTS2 regions. In Central Macedonia, the observed values start at similar levels and a significant growth over the years is noted, while in Western Macedonia, a constant decline over the same 10-year period is observed. This is an explicit indication of the long-term inadequacy of basic development indicators in the region of Western Macedonia, implying the necessity of the implementation of core regional boosters such as digitisation.

Similar findings are shown in Fig. 2, where population change by NUTS2 regions values are presented. Again, there is a clear downturn noted in Western Macedonia in comparison to Central Macedonia shown in Fig. 2.

\section{ICT Parameters}

In general, the discrepancies of the primary ICT indicators between the two regions are mainly due to the significantly larger GDP level and population of Central Macedonia in comparison to Western Macedonia. The significantly low
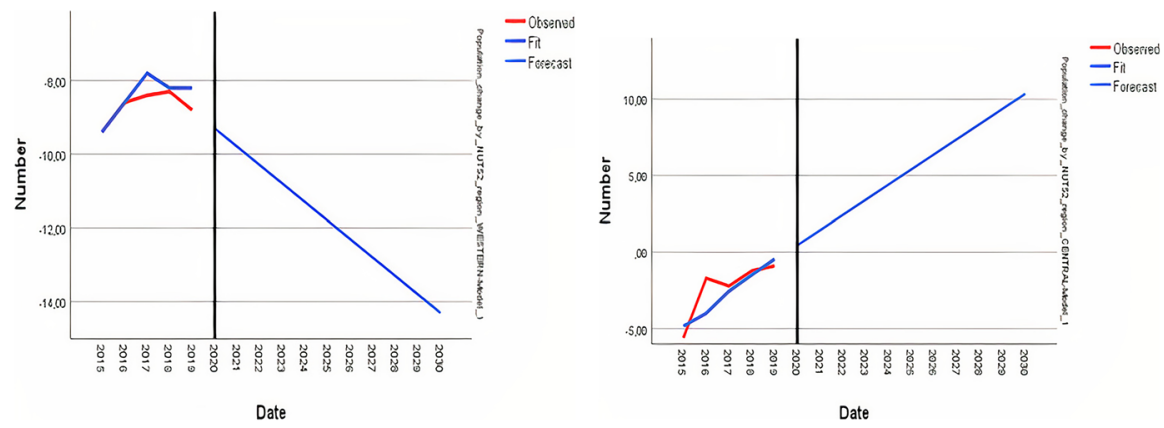

Fig. 2 Population change by NUTS2 regions observed and forecast values for Central and Western Macedonia 
demand of ICT products/services in the region of Western Macedonia is primarily caused by the low-income levels in the region. The level of ICT adoption in the two regions can be investigated through a series of ICT-based indicators, expressing basic ICT performance at each distinct operation. Two basic indicators that reveal the familiarity of the local workforce to ICT are:

1. $\mathrm{PC}$

2. Internet usage (indicators 1 and 2)

These fully quantitative indicators have been collected from the Eurostat database of the general category of 'ICT usage in households and by individuals' regional indicators. ICT adoption is also based on the:

3. digital skills of the local workforce,

4. number of ICT companies operating in a region,

5. number of completed ICT projects and

6. total ICT contribution to economic activity (indicators 3 to 6 ).

These qualitative indicators have been collected from the RIS3 Regional Assessments of Central and Western Macedonia (Reid et al., 2012), and they are evaluated on a Likert 7-scale.

Regarding digital skills of the local workforce in the region of Western Macedonia, the research findings indicated a considerable gap according to Internet users in Greece survey while in Central Macedonia, there is a larger percentage documented, mainly due to the larger and more diversified local economy and the increased GDP levels of the region (Tsekeris \& Papaioannou, 2018). Number of ICT companies in the two regions also indicate different levels of ICT adoption. In Western Macedonia, a small number of ICT SMEs is operating in the region, primarily focusing on software support, maintenance and system integration, for public administration bodies and for the retail sector (Reid et al., 2012). On the contrary, the region of Central Macedonia hosts a high number of ICT companies, mainly focused on business software support and system integration (Giotopoulos et al., 2017). The same applies for the number of ICT projects already built in the two regions. Some of the most significant public ICT projects that have been recently concluded in the region of Western Macedonia had to do with with the installation of metropolitan access networks, the development of municipal wireless hotspots and the networking of the local university and school units to the national research and education networks (Reid et al., 2012). On the other side, Central Macedonia hosts a significantly higher number of completed ICT projects in transportation (Tsekeris et al., 2013), networking of public institutions and digitisation of cultural and historical monuments (Reid et al., 2012). In total, ICT projects in Greece reach a satisfactory level in recent years (Tsakanikas et al., 2014); however, lagging regions such as Western Macedonia still need further ICT investments. ICT contribution to the economic activity needs to be significantly reinforced in Western Macedonia while in Central Macedonia 
covers a relatively large proportion to total GDP of the region (Reid et al., 2012; Tsekeris \& Papaioannou, 2018; Giotopoulos et al., 2017; Tsekeris et al., 2013; Tsakanikas et al., 2014).

\section{The Systemic Overview of RIS}

\section{The SD Model}

Stocks and flows, along with feedback loops, are the two central concepts of SD theory. Stocks are the accumulations of the inflows and the outflows within the system of research. SD uses a particular diagramming notation for stocks and flows. Stocks are defined by the stock equations, as the time integrals of the net flows. Flows are defined by the rate equations, as the time functions of stocks and system parameters. In SD models, the stock and flow perspective represent time as unfolding continuously; events can happen at any time, change can occur continuously. The structure of a system in SD methodology is captured by linking the stock and flow structure with feedback mechanisms and is represented by stock-flow diagram, which is the graphical representation of the mathematical model [26]. The arrows (causal links) inside a stock-flow diagram represent the relations among variables, where the physical flow is shown by a continuous line and the information flow by dotted lines. The direction of the causal links displays the direction of the effect. Signs ' + ' or - at the end of these links exhibit the sign of the effect. When the sign is ' + ', the variables change in the same direction; otherwise, they change in the opposite one. The stock-flow diagram is translated to a system of differential equations, which is then solved via simulation, supported nowadays by high graphical simulation programs such as Vensim®, PowerSim ${ }^{\circledR}$, i-think ${ }^{\circledR}$, and Stella ${ }^{\circledR}$. In this study, we use the Powersim 10 modeling tool. The generic stock-flow diagram of RIS system is shown in Fig. 3. To improve appearance and distinction among the variables, stock variables are written into rectangles.

As shown in Fig. 3, regional development is increased by Rin of $\mathrm{RD}$ and is decreased by depreciation of RD. Rin of RD is the result of stock variables product innovation and process innovation, and auxiliaries that predict population change, real growth of GVA and tertiary educational attainment. Product innovation (Prod. In.) increases in tandem with the number of researchers, the percentage of those who contribute to $R \& D$, and the percentage of those who are active in Prod.In. Process innovation (Proc.In.) is influenced by the Proc.In growth rate, which is influenced by the Proc.In growth rate according to a delay function, as well as the number of researchers working on Proc.In (in a similar way to Prod.In.). Due to the depreciation of knowledge over time, both Prod.In. and Proc.In. are lowered according to a rate of depreciation (depreciation of Prod.In. and depreciation of Proc.In., respectively). The influence diagram of the computation of Prod.In. and Proc.In. is shown in Fig. 4.

Aside from Prod.In. and Proc.In., there is the knowledge network subsystem, which includes explicit (EK) and tacit knowledge (TK). R\&D capacity produces 


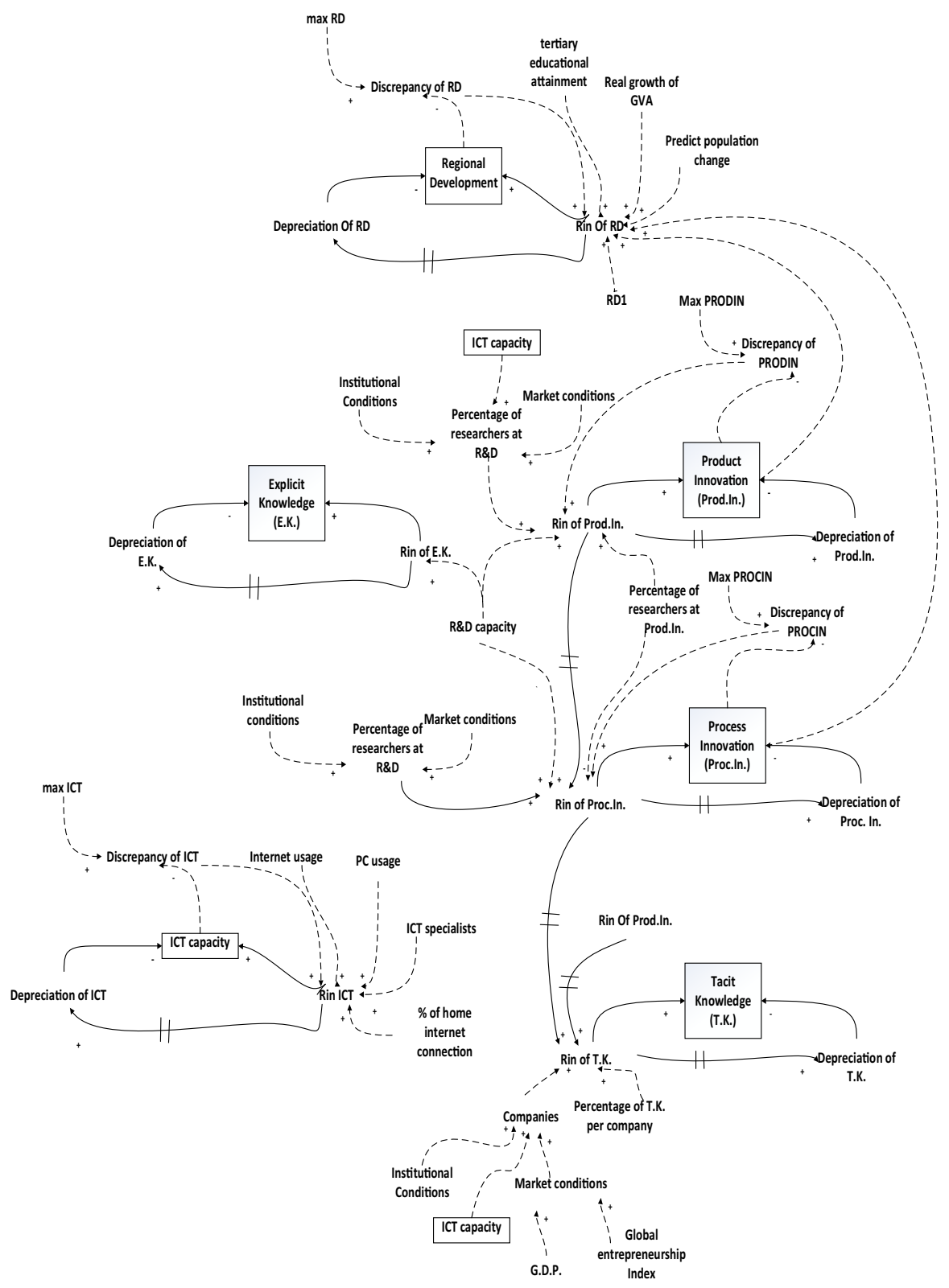

Fig. 3 Generic stock and flow diagram of the RIS under study

explicit information as a result of the research process. Tacit knowledge, on the other hand, is a result of businesses' day-to-day operations and the use of both Prod. In. and Proc.In. In a similar way to Prod.In. and Proc.In., explicit and tacit knowledge are reduced by a rate of depreciation. 


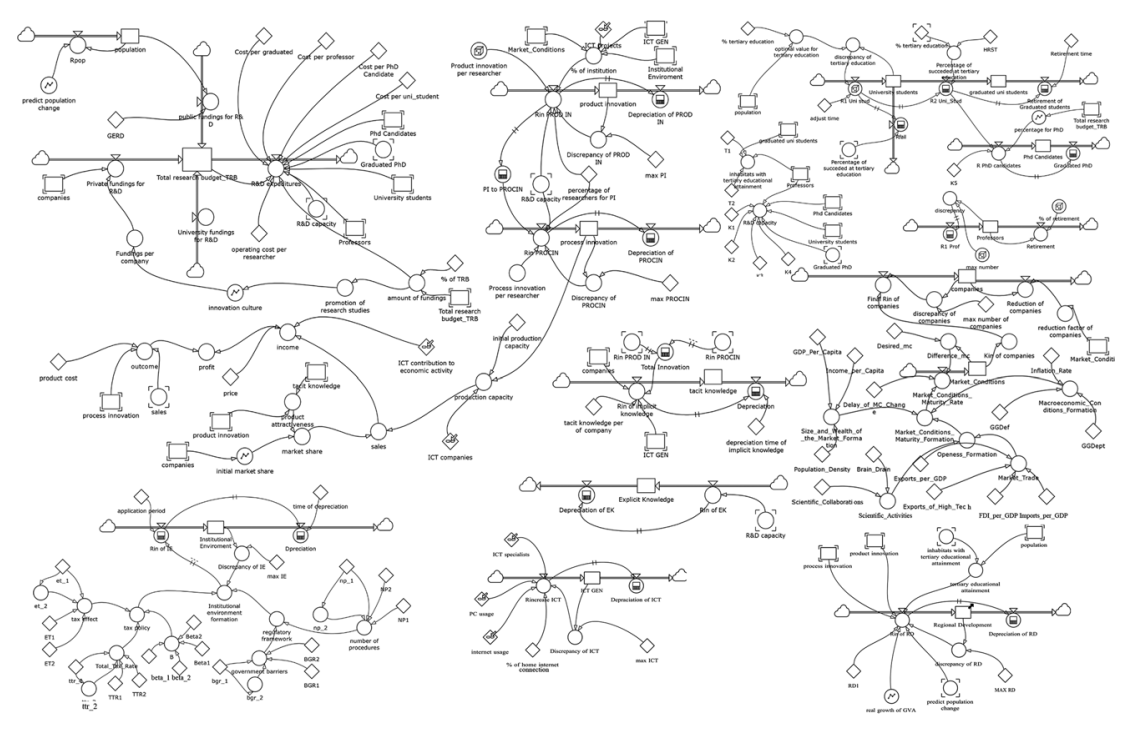

Fig. 4 Stock and flow diagram of the RIS under study in Powersim 10

The institutional environment generally refers to the models, habits and value system of the people as well as to the 'social organisation' in a regional or national level (OECD, 1999). Essentially, the institutional environment is based on the social and cultural environment of the region, since each social group directs, structures, operates, operates and acts (Tomlinson, 1998). Institutional conditions vary depending on the rate of change in the institutional setting and the depreciation of the institutional setting. The rate of change in the institutional environment changes with the formation of the institutional environment, which is then increased by two variables: the tax policy and the regulatory framework. Literature-based tax policy is quantified using three indicators: Tax Impact, Index B and Tax Level. Therefore, the regulatory framework is quantified with the help of two indicators: the number of procedures and obstacles to state regulations.

Prod.In. and T.K. both help to enhancing the attractiveness of products in comparison to rivals in order to improve each company's market share. Proc.In., on the other hand, aids in reducing the cost of producing products. All of the above have the effect of increasing the profit generated per business.

The number of companies fluctuates according to market conditions, institutional conditions, and the ICT capacity. Market conditions are key elements for the activity of the players of a RIS (OECD, 1999). Freeman and Soete (1997) emphasise the importance of a local network of companies, education, R\&D infrastructure and the local institutional framework, saying that they are the factors that, together with the market environment, play a very important role in innovation systems and in development. Market conditions in turn are influenced by the market maturity rate, which in turn is increased by the Market Maturity Format, the Global Entrepreneurship Index, and the GDP. The formulation of market size and wealth, the formulation of market opening and the formulation of macroeconomic conditions increase the 
formulation of market conditions. Market opening configuration is increased by two variables, the scientific activities and the technological trade. Two indicators of the literature enhance scientific activities, talent leakage and scientific collaborations. Technology trade comprises four indicators, IDI/GDP (international direct investment per gross domestic product), imports/GDP, exports/GDP and exports of high technology products as a share of total exports. Finally, in a general context, macroeconomic conditions determine the general business climate of a market, which in turn affects the innovation climate in peripheral innovation systems (Van der Steen, 1999). In our study, regarding macroeconomic conditions, we will deal with three indicators, public deficits, debt and inflation.

Literature review revealed that to capture research activities of RIS' actors, the expenditures for R\&D activities are key indicators of the innovation entry (CIS, Frascati Manual) and in fact the close relationship between R\&D expenditures and research activities results has been empirically captured. To measure the level of research activities in our study we focus on investing in R\&D-related activities at a macroeconomic level considering three different types of R\&D expenditure data. These types of data are state, university and private R\&D expenditures as a percentage of GDP. State R\&D Grants, the amount from the university R\&D budget, and Private Enterprise R\&D Grants all add to the overall $R \& D$ budget. The total $R \& D$ budget, on the other hand, is decreased by total R\&D expenditures, namely both researchers' wages and other operational costs for effective research and development. Private Enterprise Grants, in turn, are influenced by the total number of businesses as well as the amount of subsidy each one receives, a variable that rises with the growth of the innovation culture. Appropriate innovation promotion initiatives, which are also part of the total R\&D budget spending, are developed in order to enhance the culture of innovation. The quantity of government grants is determined by the GERD price for each region, as well as the population of that region. The Gini value (regional inequality calculation index) relating to that region has an inversely proportionate effect on the population of that region.

The stock-flow diagram of the regional innovation system, which has been developed using the Powersim ${ }^{\circledR} 10$ software, is exhibited in Fig. 4. The diagram is constructed using building blocks (variables) categorised as stocks, flows, delays, converters, and constants. Stock variables (symbolised by rectangles) are the state variables, flow variables (symbolised by valves) are the rates of change in stock variables, and they represent those activities, which fill in or drain the stock variables. Delays (represented by circles with a rectangular) introduce time delay in material or information channels. Converters (represented by circles) are intermediate variables used for auxiliary calculations. Constants (represented by rhombuses) are the model parameters. Finally, the connectors, represented by simple arrows, are the information links representing the cause and effects within the model structure, while the double line arrows represent physical flows. Double lines across the arrows indicate a delayed information.

The mathematical representation of regional development is given by the following equations. 


$$
\begin{aligned}
& \text { Regional Development }(\mathrm{t})=\text { Regional Development }(\mathrm{t}=0) \\
& +\int_{0}^{\mathrm{t}}[\operatorname{Rin} \text { of } \mathrm{RD}(\mathrm{t})-\text { Depreciation of } \mathrm{RD}(\mathrm{t})] \mathrm{dt}[\text { grade }]
\end{aligned}
$$

$$
\begin{aligned}
\text { Rin } & =\text { MIN }(\text { discrepancy of RD; } 1,4 \\
& * \text { (real growth of GVA } \\
& + \text { process innovation }+ \text { product innovation } \\
& + \text { predict population change tertiary educational attainment }) / \text { RD } 1)[\text { grade] } / \text { year }
\end{aligned}
$$

$$
\text { discrepancy of } \mathrm{RD}(t)=\max \mathrm{RD}(t)-\text { Regional Development }(t) \text { [grade] }
$$

Equation (1) represents the stock equation for regional development in grade. By Eq. (2), Rin of RD is defined by the minimum value between the discrepancy of $\mathrm{RD}$ and the sum of the factors which affect the regional development multiplied by 1.4 , as they are five parameters which equally affect to the maximum grade which is equal to 7. The constant value RD1 represents the control period of these factors which at this model is equal to 1 time per year.

\section{Model Validation}

A wide variety of tests have been developed to check the validity of the model (Sterman, 2000). The basic criterion for SD model's validation is structure validity, which is the validity of the set of relations used in the model, as compared with the real processes.

The model's validity is checked by conducting tests suggested by the SD literature (Barlas \& Diker, 2000; Sterman, 2000). First, we checked the model's dimensional consistency. Then, we conducted extreme conditions tests checking whether the model behaves realistically even under extreme situations. For example, we checked that if R\&D capacity equals to zero then product innovation and process innovation remained stable and equal to their initial value, since product innovation rate and process innovation rate are mainly affected by $R \& D$ capacity. The model employs the Euler integration method with integrating time-step equal to 1 year. The results of the tests indicated no integrating errors.

Moreover, since the model's shortest time constant is set to one year and standard practice in SD suggests that the integrating time step (dt) should be maximum $1 / 4$ of the shortest time constant in the model, we set the dt initially at $1 / 4$ year and ran the model. Then we cut the $d t$ in $1 / 2$ and ran the model again. The results did not significantly change. Therefore, structural validation tests were executed, which confirmed the sensitivity of the model structure to specific parameters. 


\title{
The Effect of Smart Technologies on the Regional Development-the Case of Two Greek Regions
}

\section{Description of Regions Under Study}

\begin{abstract}
After developing the mathematical model ("The Systemc Overview of RIS" section) and estimating its parameter values ("Methodology" section), as well as checking its validity ("The Effect of Smart Technologies on the Regional Development-the Case of Two Greek Regions" section), in this section the model is simulated to study the impact of smart technologies on regional development, for the case of two Greek regions, Central Macedonia and Western Macedonia. The choice of these two regions is not random as the first is a purely urban area, while the second is considered as a provincial area.
\end{abstract}

\section{'What If' Scenario Analysis for the Two Greek Regions}

In this section, the authors identify the parameters that can be adjusted at regional level. Two 'what if' scenarios are considered, for both regions, which simulate these changes, and reflect them at the level of Regional Development for each region respectively.

According to the Digital Transformation Program (DTP) 2021-2027, Greece, and the Greek regions, respectively, have realised that the need for the transition to the digital economy and society should be treated as an immediate priority. The set of actions that DTP aims to financially support, refers to the six (6) Strategic Axes of Intervention of the Digital Transformation Bible 2020 - 2025 and are summarised as follows:

\section{Connectivity}

2. Digital abilities and skills

3. Digital business transformation

4. Digital public services

5. Digital innovation

6. Utilisation of advanced technologies

In addition, according to the evaluation of the Regional Smart Specialization Strategy that was conducted for all Greek regions, the following findings emerged regarding the field of smart technologies for the two regions that are investigated in this paper:

\section{Western Macedonia}

The primary mean for the region to incorporate ICT in the RIS3 strategy is to reinforce the ICT level of the most important factors of the regional economy, i.e. 
energy, mining, healthcare, tourism, agriculture and transport. The region should direct research on the investigation of policy tools that are able to offer incentives for innovative IT products and services produced by local businesses and also direct funds for the effective transformation of traditional enterprises towards the implementation an ICT-based business model.

A key ICT factor for strengthening the competitiveness of an economy at both regional and national level is the broadband expansion at both wireline and wireless form. Keeping talented ICT workforce should be a top priority for the policy makers along with attracting new ICT-based firms by increasing the demand for enhanced and innovative ICT services. The development of the best digital capabilities of the local workforce plays a crucial role in the societal well-being as well as the effective operation of the state and the economy. Deficiencies in advanced digital skills negatively affect productivity, as they delay the adoption of advanced digital technologies. ${ }^{1}$

Moreover, special care must be given to the role of the private sector in taking up a part of the risk of the scheduled ICT investments, in order to secure the long-term liability of the proposed business projects.

\section{Central Macedonia}

As in the region of Western Macedonia's case, a crucial ICT factor for increasing the competitiveness of the local economy, is the broadband expansion at both wireline and wireless form. Furthermore, digital skills of the local workforce should be also enhanced, through the implementation of a new holistic educational and research framework, specifically focused on ICT and innovative digital technologies.

ICT services' sector alone can be a lever of transformation of the region of Central Macedonia to a startup hub in the broader region of Eastern Europe, with the private sector to also play a major role in the investment process.

To address the above challenges, the authors use the RIS model to present the effect of the change of the independent variables presented in Tables 1 and 2 on the regional development of the two regions.

In order to examine the response of the scenarios presented above to each region, we execute the SD model for a simulation horizon of 10 years with timestep equal to 1 year.

\section{Results}

The results of the SD model are calculated for each scenario presented in Tables 1 and 2, and thus, the results for each region are obtained which are depicted in Figs. 5 and 7 where we see the two curves for the price of regional development that correspond to the 2 scenarios under study.

From fig. 5, we conclude to the following: 
Table 1 Western Macedonia

\begin{tabular}{llll}
\hline Independent variables & Initial scenario & Scenario 1 & Scenario 2 \\
\hline 1.PC usage & $32 \%$ & $+5 \%$ & $+10 \%$ \\
2.Internet usage & $32 \%$ & $+5 \%$ & $+10 \%$ \\
3.Digital skills/ICT specialists & 2 & 4 & 5 \\
4.ICT companies & 2 & 4 & 5 \\
5.ICT projects & 3 & 4 & 5 \\
6.ICT contribution to economic activity & 1 & 3 & 4 \\
\hline
\end{tabular}

Table 2 Central Macedonia

\begin{tabular}{llll}
\hline Independent variables & Initial scenario & Scenario 1 & Scenario 2 \\
\hline 1.PC usage & $42.4 \%$ & $+5 \%$ & $+10 \%$ \\
2.Internet usage & $41.3 \%$ & $+5 \%$ & $+10 \%$ \\
3.Digital skills/ICT specialists & 4 & 5 & 6 \\
4.ICT companies & 4 & 5 & 6 \\
5.ICT projects & 4 & 5 & 6 \\
6.ICT contribution to economic activity & 2 & 4 & 5 \\
\hline
\end{tabular}

- In case of each scenario, the system does not reach the equilibrium, in the time horizon of decade, due to both the low-price levels of the independent constants variables describing the ICT and the variables describing the environment of the region such as its population. Also, the reason for the low levels of improvement of regional development, is because most ICT indicators relate to the infrastructures of the region, for this reason we expect to improve more difficult and at a slower pace.

- Even though the system does not reach the equilibrium, we observe an exponential growth of regional development during the simulation period. In addition, the better prices for the ICT parameters the bigger incretion rate of the regional development.

- To find the time that the system reaches the equilibrium, we simulate the SD model for 20 years. The results are shown in Fig. 6. We observe that the equilibrium of the regional development is 6.10 and it appears at the 14th year.

In terms of Central Macedonia, the results are presented in Fig. 7. The main findings are the following:

- The equilibrium of regional Development is equal to 6.20 and appears at the 8th year of the simulation, sooner than the case of Western Macedonia, which is result of the higher price levels of the independent constants variables describing the ICT and the variables describing the environment of the region such as its population. 


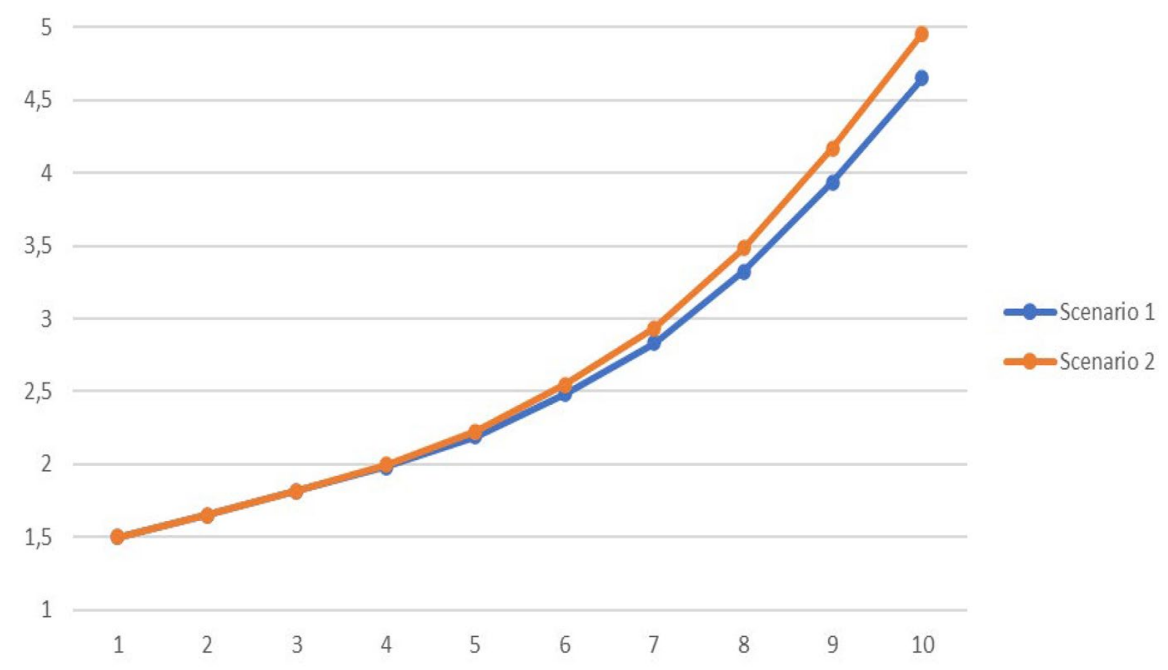

Fig. 5 Regional development of Western Macedonia

- We observe an exponential growth of regional development during the simulation period, until the system reaches the equilibrium. In addition, the better prices for the ICT parameters the bigger incretion rate of the regional development, and as a result reaches equilibrium sooner.

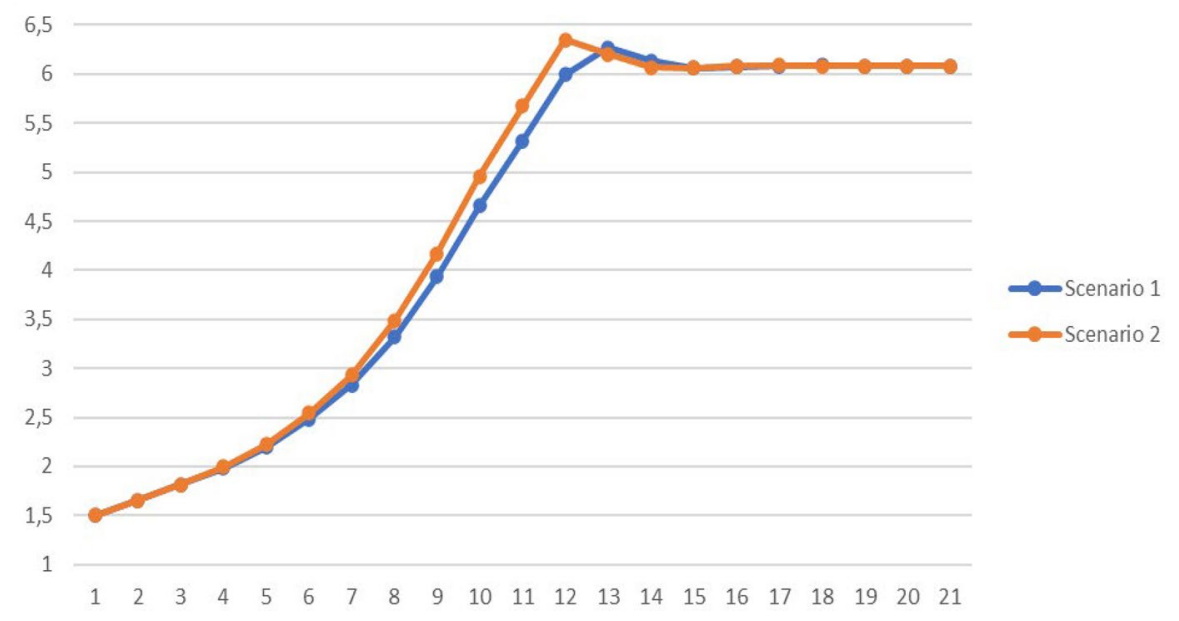

Fig. 6 Equilibrium of SD model for Western Macedonia 


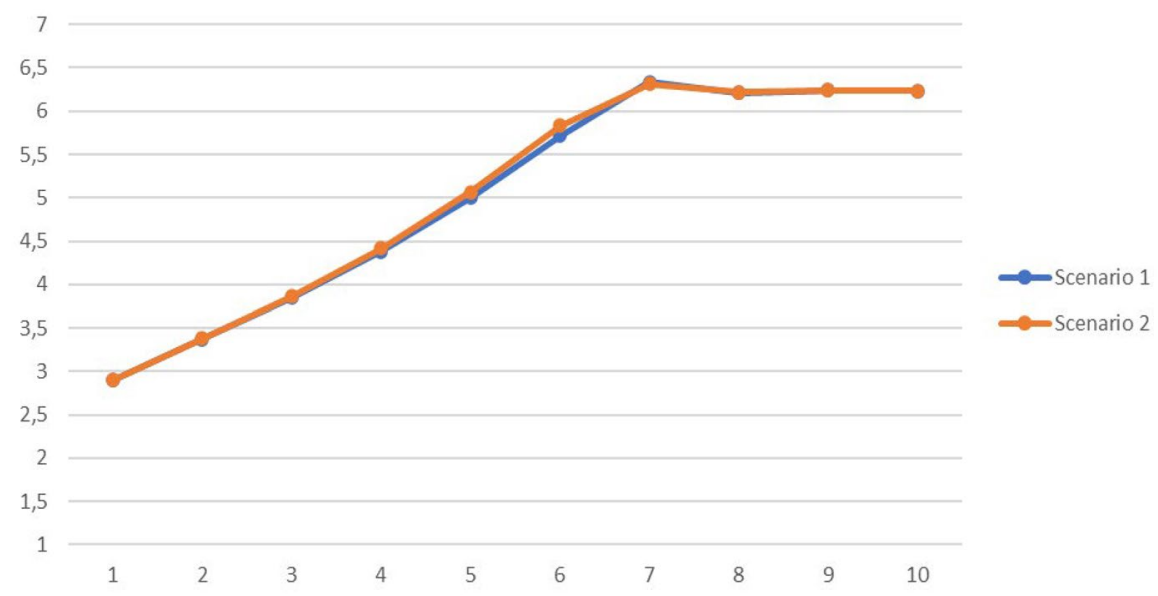

Fig. 7 Regional development of Central Macedonia

\section{Conclusions and Proposals for Further Research}

The present research aims to deepen the study on the structure of the RIS and more specifically, on the interactions between the actors involved in it and to propose policies in order to improve regional development. To achieve this goal a mathematical model is developed specifically designed to study the structure of the RIS. The results of the mathematical model simulations give rise to policies that promote regional development. Both the development of the mathematical model and the regional development scenarios were aimed at contributing to the research activity for the understanding of the interactions between the actors involved in a RIS, but also with the aim of their applicability by policy makers at regional level.

The findings from the simulations reveal an overall impact of the implementation of the two scenarios which significantly affects the regional development of both regions under study, with Central Macedonia clearly showing better growth rates. This was to be expected given the fact that Central Macedonia starts with better levels of regional development compared to Western Macedonia, as well as most of the smart technology indicators we have changed are at higher initial levels. The simulations also show that the time required for a significant impact on regional development is quite long, Western Macedonia even needs more time, due to the fact that the indicators of smart technologies used are directly related to infrastructure development, for this is why they improve harder and slower.

The mathematical model developed could well be adapted to the data of other regions. The use of the actors involved in the RIS, based on rich bibliographic research, led to the creation of a general model of the RIS study. The model would therefore be able to help different regions to develop appropriate policies depending on the goals they have set to achieve their regional development. 
Moreover, the mathematical model developed in the context of this research could also be enriched so that it can be used in a larger number of practical applications. In particular, the influences of sectoral innovation systems on regional development could be incorporated to study other effects. For example, it would be useful to study the impact of the existence and operation of virtual clusters operating at sectoral and regional level.

The main problem we encountered in the present survey was the availability of indicators at regional level. In a subsequent survey, either the marking of indicators through questionnaires or the application of spatial microsimulation can be used to estimate the levels of additional variables. According to bibliography, spatial microsimulation can be used to estimate index values at regional level if the corresponding values at national level are known.

In addition to the above proposals for future research, the following proposals for extending the model developed in the present research are of practical interest:

- The integration of business characteristics that help (or hinder) innovative activities, in order to determine how smart technologies can help directly or indirectly in the performance of innovative businesses and consequently in regional development.

- The impact of on-line R\&D networks is not extensively studied in our model. The study of this factor will show the role of networks in the flow of knowledge within a RIS.

- Regarding the virtual clusters mentioned above, in the model we could propose policies that will result from a "cluster approach" of technology and innovation policy.

\footnotetext{
Author Contribution Conceptualisation, E.S, A.A, N.C and Y.B.; data curation, A.A and E.S..; formal analysis, E.S., A.A, N.C and Y.B.; funding acquisition, A.A., E.S., N.C. and Y.B.; investigation, A.A and E.S..; methodology, E.K. and E.S.; project administration, Y.B.; resources, Y.B., and E.S.; software, E.K. and E.S.; supervision, N.C., Y.B. and E.S; validation, E.K.; visualisation, E.S, A.A and E.K.; writing original draft, E.S, A.A and E.K.; writing review and editing, P E.S, A.A and E.K.. All authors have read and agreed to the published version of the manuscript.
}

Funding This research was sponsored under the ack "Researcher Support - Emphasis on Young Researchers - round B” of Operational Program NSRF 2014-2020.

Open Access This article is licensed under a Creative Commons Attribution 4.0 International License, which permits use, sharing, adaptation, distribution and reproduction in any medium or format, as long as you give appropriate credit to the original author(s) and the source, provide a link to the Creative Commons licence, and indicate if changes were made. The images or other third party material in this article are included in the article's Creative Commons licence, unless indicated otherwise in a credit line to the material. If material is not included in the article's Creative Commons licence and your intended use is not permitted by statutory regulation or exceeds the permitted use, you will need to obtain permission directly from the copyright holder. To view a copy of this licence, visit http://creativecommons.org/ licenses/by/4.0/. 


\section{References}

Asheim, B., \& Coenen, L. (2005). Knowledge bases and regional innovation systems: Comparing Nordic Clusters. Research Policy, 34, 1173-1190. https://doi.org/10.1016/j.respol.2005.03.013

Barlas, Y., \& Diker, V. (2000). A dynamic simulation game (UNIGAME) for strategic university management. Simulation \& Gaming - Simulat Gaming, 31.

Carayannis, E., Dezi, L., Gregori, G., \& Calo, E. (2021a). Smart environments and techno-centric and human-centric innovations for Industry and Society 5.0: A quintuple helix innovation system view towards smart, sustainable, and inclusive solutions. Journal of the Knowledge Economy. https://doi. org/10.1007/s13132-021-00763-4.

Carayannis, E., Christodoulou, K., Christodoulou, P., Chatzichristofis, S., \& Zinonos, Z. (2021b). Known unknowns in an era of technological and viral disruptions-implications for theory, policy, and practice. Journal of the Knowledge Economy. https://doi.org/10.1007/s13132-020-00719-0

Cooke, P. (2004). The regional innovation system in Wales: evolution or eclipse?

Cooke P., Braczyk H., \& Heidenreich M. (eds.). (1998). Regional Innovation Systems. (1st edition) London: UCL Press.

Coyle, R. G. (1996). System Dynamics Modelling: A Practical Approach. Chapman \& Hall.

Doloreux, D. (2003). 'Regional Innovation Systems in the Periphery: The case of the Beauce in Quebec (Canada). International Journal of Innovation Management, 7(1), 67-94.

Doloreux, D., \& Parto, S. (2005). Regional innovation systems: Current discourse and unresolved issues. Technology in Society, Elsevier, 27(2), 133-153.

Edquist, C. (1997). Systems of Innovation: Technologies, Institutions and Organizations.

Erkko A. (2005). Evaluation of RTD in regional systems of innovation. European Planning Studies, 6, 2 , 131-140.

Eversole, R., \& Martin, J. (2005) Attending 'Sheepvention': Culture, Identity and Rural Events. Rural Society, 15(2),148-164. ISSN 1037-1656.

Forrester, J. W. (1961). Industrial Dynamics. MIT Press.

Freeman, C. (1987). Technology Policy and Economic Performance: Lesson from Japan. Pinter Publisher.

Freeman, C., \& Soete, L. (1997). The Economics of Industrial Innovation.

Geels, F. (2002). Technological transitions as evolutionary reconfiguration processes: A multi-level perspective and a case-study. Research Policy. 31.

Giotopoulos, I., Kontolaimou, A., Korra, E., \& Tsakanikas, A. (2017). What drives ICT adoption by SMEs? Evidence from a large-scale survey in Greece. Journal of Business Research, 81, 60-69.

Jeremy, H. (2006). Intermediation and the role of intermediaries in innovation. Research Policy, 35(5), $715-728$.

Johnson, R. (1997). Examining the Validity Structure of Qualitative Research. Education, 118, 2. Research Librarypg. 282. Winter.

Kilintzis, P., Samara, E., Carayannis, E., \& Bakouros, Y. (2020). Business model innovation in Greece: Its effect on organizational sustainability. Journal of the Knowledge Economy, 11(3), 949-967.

Komninos, N. (2018). Internet platforms, innovation and growth under the 'smart everything' paradigm. In proceedings of the 20th Scientific Conference. Association of Greek Regional Scientists, Regions at a Turning Point: Post-Digital Communities, New Regionalism and Renationalisation - Sustainable Development Implications, Athens, 2018, 119-125.

Komninos, N. (2006). The architecture of intelligent cities: Integrating human, collective and artificial intelligence to enhance knowledge and innovation. IET Conference Publications, 13-20 https://doi. org/10.1049/cp:20060620

Lundvall, B. A. (1992). National systems of innovation: Towards a theory of innovation and interactive learning. Pinter Publishers.

Lundvall, K., \& Battese, G. E. (2000). Firm size, age and efficiency: Evidence from Kenyan manufacturing firms. Journal of Development Studies, 36, 146-163.

McCarthy, M., Best, M., \& Betts, R. (2010). Climate change in cities due to global warming and urban effects. Geophysical Research Letters, 37, https://doi.org/10.1029/2010GL042845

Nauwelaers, C., \& Wintjes, R. (2008). Innovation policy in Europe: Measurement and strategy.

Nelson, R. R. (1993). National innovation systems: A comparative analysis. University of Illinois at Urbana-Champaign's Academy for aEntrepreneurial Leadership Historical Research Reference in Entrepreneurship.

Niosi, J. (2000a). Canada’s National System of Innovation. McGill-Queen's University Press. 
Niosi, J. (2000b). Regional systems of innovation market pull and government push.

OECD. (1999). Managing national innovation systems. OECD.

Rajkumar, S. (2010). Art of communication in project management. Paper presented at PMI ${ }^{\circ}$ Research Conference: Defining the Future of Project Management, Washington, DC. Newtown Square, PA: Project Management Institute.

Reid, A., Komninos, N., Sanchez, J., \& Tsanakas, P. (2012). RIS3 assessment: Central Macedonia. A report to the European Commission. Directorate General for Regional Policy, Unit I3-Greece \& Cyprus, $1-24$.

Sotirelis, P., Nakopoulos, P., Valvi, T., Grigoroudis, E., \& Carayannis, E. (2021). Measuring smart city performance: A multiple criteria decision analysis approach. Journal of the Knowledge Economy, 1-29.

Sefertzi, E. (Ed.). (1998). Innovation: System areas, technology transfer and development in Greece. Gutenberg.

Sharma, R., Mithas, S., \& Kankanhalli, A. (2014). Transforming decision-making processes: A research agenda for understanding the impact of business analytics on organisations. European Journal of Information Systems., 23, 433-441.

Sterman, J. D. (2000). Business Dynamics: Systems Thinking and Modeling for a Complex World. Irwin McGraw-Hill.

Todtling, F., \& Trippl, M. (2005). One size fits all? Towards a differentiated regional innovation policy approach. Research Policy, 34, 1203-1219.

Tomlinson, B. (Ed.). (1998). Materials development in language teaching. Cambridge University Press.

Tsakanikas, A., Danchev, S., Giotopoulos, I., Korra, E., \& Pavlou, G. (2014). ICT adoption and digital growth in Greece. Foundation for Economic \& Industrial Research, 13, 1-91.

Tsekeris, T., Tsekeris, C., Koskinas, K., \& Lavdas, M. (2013). Intelligent transport systems and regional digital convergence in Greece. Journal of Transport Literature, 7, 297-318.

Tsekeris, T., \& Papaioannou, S. (2018). Regional determinants of technical efficiency: Evidence from the Greek economy. Regional Studies, 52, 1398-1409.

Van der Steen, M. (1999). Evolutionary systems of innovation: A Veblian-oriented study into the role of the government factor. University of Twente.

Viale, R., \& Pozzali, A. (2010). Complex adaptive systems and the evolutionary triple helix. Critical Sociology, 36, 575-594. https://doi.org/10.1177/0896920510365923

Publisher's Note Springer Nature remains neutral with regard to jurisdictional claims in published maps and institutional affiliations. 